\title{
A Basic Study on the Spatial Cognition Analysis for the Prevention of Museum Robbery
}

\author{
Kyungmo Koo ${ }^{1}$, Youhee $\mathrm{Heo}^{2}$ and Heangwoo $\mathrm{Lee}^{3 *}$ \\ ${ }^{1,2}$ Department of Interior Design, College of Design, Sangmyung University, Korea \\ ${ }^{3}$ Major of Space Design, College of Design, Sangmyung University, Korea

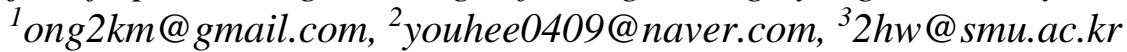

\begin{abstract}
Recently, the demand for museums has increased to raise the cultural level of the general public and policies have been established to build more museum facilities. The expansion of museums has led to more museum heists, so security has become an important issue for museums by analyzing vulnerable areas within the premises. However, there is not enough research on the security of museums. Therefore, the purpose of this study is to establish basic data for future museum designs by analyzing the spatial structure of museums and the areas vulnerable to theft. This study used space syntax to analyze the vulnerable areas of a museum and derived areas with low spatial awareness. The main findings are as follows. 1) Based on the global integration of the museum, this study derived convex spaces with both low global and local integration values, which were considered to have low accessibility to other spaces and low spatial significance. 2) This study derived the minimum value of the local integration of the museum, and this convex identified the most vulnerable space for theft. Therefore, it is necessary to design security and control facilities for spaces vulnerable to theft when designing museums in the future. Based on this, it is possible to predict areas vulnerable to theft, and use this study as basic data to design museums in the future.
\end{abstract}

Keywords: Museum, Spatial structure, Security, Space syntax

\section{Introduction}

Recently, the Korean government has implemented policies to expand museums and art galleries to raise the cultural level of the people. In particular, the government has announced plans to build 140 new museums and art galleries in Korea, and various studies are being conducted on the spatial composition, circulation, color, and exhibition methods related to museums [1][2][3][4]. However, the expansion of museums has led to more museum heists, so security has emerged as an important issue due to the nature of the artifacts in the museums [5]. Cases of museum heists due to poor security include the 2019 Dresden heist, in which several criminals lifted artifacts worth $€ 1.3$ trillion from the Grünes Gewölbe in Dresden, Germany. And, Van Gogh paintings were stolen from a Dutch museum that had closed because of COVID-19 in March 2020. Cases in Korea include the theft of four national treasures from the Gongju National Museum on May 15, 2003. Nevertheless, the number of studies on spatial planning against museum heists is still remarkably low [6], but such

Article history:

Received (June 28, 2020), Review Result (August 4, 2020), Accepted (September 8, 2020) 
research is necessary because most of the museums that have recently been designed and built are open spaces for social communities.

Therefore, the purpose of this study is to build data for designing museums in the future by analyzing and predicting the spaces that are vulnerable to theft in an actual museum in Korea.

\section{Consideration of museum analysis methods}

\subsection{The composition of museums and research trends}

The concept of a museum varies depending on the definition of different institutions. However, in general, museums are social spaces that collect, preserve, deliver, and exhibit various objects of artistic, cultural, historical, or scientific importance, and are active spaces for social interaction where the visitors can experience valuable or new things [7]. According to the International Council of Museums(ICOM) Statutes, a museum is a permanent establishment, administered in the general interest, for the purpose of preserving, studying, and enhancing by various means and, in particular, of exhibiting to the public for its delectation and instruction groups of objects and specimens of cultural value: artistic, historical, scientific and technological collections, botanical and zoological gardens, and aquariums. Public libraries and public archival institutions maintaining permanent exhibition rooms are also considered to be museums [8]. According to the International Council of Museums, a museum is a non-profit, permanent institution in the service of society and its development. Open to the public, the museum acquires, conserves, researches, communicates, and exhibits the tangible and intangible heritage of humanity and its environment for the purposes of education, study, and enjoyment. Museums are also divided into national museums, public museums, and private museums, depending on the founder. According to the collection of artifacts, museums are also divided into general and specialized museums. General museums care for a collection of various exhibits and specialized museums usually specialize in fields such as archeology, history, art history, anthropology, folklore, natural history, industry, communication, transportation, medicine, and calligraphy. The composition of a museum is classified into exhibition space, storage space, work space, and public space according to its nature. First, the exhibition space is divided into exhibition facilities and exhibition support facilities. This space should be carefully planned according to the exhibition program because it occupies the largest area as a single function among the unit spaces and is most frequently used by visitors. Second, the storage space preserves the collections in museums. Sufficient space should be prepared by considering the increase in artifacts in the future. Storage spaces usually include unloading facilities to unload, package, and dismantle artifacts and other management and auxiliary facilities. Third, the work space is designated for museum employees and is generally located in a place that does not interfere with the visitors' circulation. Fourth, public spaces encourage visitors to participate in various programs, and this trend is increasing as the function of museums is subdivided into complex cultural spaces.

Most of the previous studies focused on the spatial composition, exhibition methods, hierarchies, and visitor circulation in museums [9]. However, research is also being conducted on the security of museums which this study aims to analyze, and this means that the study on the security of museums covered in this study has its significance.

\subsection{Consideration of analysis methodology}


This study used space syntax to analyze the areas vulnerable to theft according to the spatial structure of museums. Space syntax is suitable for this study because it divides the convex spaces of the internal space into unit spaces and quantitatively analyzes the spatial hierarchy between the unit spaces. The convex space that divides a certain space refers to the unit space of an open space where one can recognize all indoor spaces as a visual point, where it is possible to analyze the links between the unit spaces by dividing the indoor space into convex spaces [10]. In particular, space syntax can derive the areas vulnerable to theft in museums by deriving the outer perimeter of spaces that are rarely used and low-profile spaces through spatial analysis. The following describes the quantitative indicators of space syntax. The global integration shows the overall relationship of all spaces, including the spaces to be analyzed as well as the spaces in the surrounding area. In general, a global integration below 1 indicates segregation in which the spaces are distanced far from each other, but a value higher than 1.7 indicates integration indicating that all spaces are distanced closely to all others. That is, higher global integrations of a specific space mean that this space is of great significance to the overall spatial structure and that it has access to all other spaces in the building or city to be analyzed. On the other hand, a space with low global integration means less access to all other spaces and less significance in terms of spatial structure. Local integration shows the degree of integration within a certain range near a specific space and quantifies the accessibility of a specific unit convex space based on recognizing convex spaces with a spatial depth of 3 while moving. That is, if the accessibility of a certain unit convex space to the convex spaces in the entire area is the global integration, the accessibility of a specific unit space considering human cognitive ability is the local integration. Therefore, in terms of summarizing the indicators related to integration, the areas with higher integration are areas with higher spatial awareness and less concern of theft. Whereas, areas with lower integration may have concerns about theft [11].

\section{Analysis of vulnerable areas according to the spatial composition of museums}

\subsection{Selecting the analysis target}

As shown in [Table 1], this study selected the Gwangju National Museum as the analysis target based on the following. The museum is located in Korea and is currently operating, and this study intended to select a museum in other regions excluding the Seoul metropolitan area. The museum also has a total floor area of over $1,000 \mathrm{~m}^{2}$, and more than $51 \%$ of the exhibition and storage spaces are vulnerable to theft. Finally, the study candidates were limited to museums specializing in specific antiquities for at least 10 years.

Table 1. Overview of Gwangju National Museum

\begin{tabular}{|c|c|c|}
\hline \multicolumn{2}{|c|}{ Museum } & Gwangju National Museum \\
\hline \multicolumn{2}{|c|}{ Location } & Gwangju, South Korea \\
\hline \multicolumn{2}{|c|}{ Exhibition theme } & $\begin{array}{l}\text { Artifacts (Artifacts from the Prehistoric and Baekje periods, } \\
\text { Buddhist art, etc.) }\end{array}$ \\
\hline \multicolumn{2}{|c|}{ Opened } & October 1994 \\
\hline \multicolumn{2}{|c|}{ Total building area (m2) } & 7,499 \\
\hline \multirow{2}{*}{$\begin{array}{c}\text { Spatial } \\
\text { composition }\end{array}$} & Exhibition space & $31.2 \%$ \\
\hline & Storage space & $20.5 \%$ \\
\hline
\end{tabular}




\begin{tabular}{|c|c|c|}
\hline & Work space & $14.5 \%$ \\
\cline { 2 - 3 } & Public space & $19.3 \%$ \\
\cline { 2 - 3 } & Other & $14.5 \%$ \\
\hline
\end{tabular}

\subsection{Analysis method}

This study analyzed the areas vulnerable to theft according to the spatial structure of a museum using space syntax by dividing convex spaces through zoning the components in the floor plan. This study grouped the spaces in the museum into exhibition, storage, work, and other public spaces. Second, the spaces in the museum's floor plan were divided into convex space units, in which homogeneous spaces except corridors were regarded as one convex space even if the visibility was blocked. Third, the global and local integration of the divided convex spaces were derived by using space syntax, and areas with both low global and local integrations were considered to be spaces with low visitor usage and awareness. Accordingly, it is possible to predict the areas vulnerable to theft in museums by deriving the convex spaces with both low global and local integrations.

\subsection{Analysis results and discussion}

This study analyzed the areas vulnerable to theft according to the spatial structure of a museum using space syntax by dividing convex spaces through zoning the components in the floor plan.

First, the minimum, maximum, and mean global integration of the Gwangju National Museum were 0.6, 2.5, and 1.57, respectively. As shown in [Table 2], the convex spaces that show low global integration based on the analysis results of global integration above are spaces with low integration in each area, and these spaces with low accessibility and significance to other spaces are generally convex spaces of the museum's outer circulations or storage spaces. Therefore, CCTVs or detectors should be installed in such areas vulnerable to theft.

Table 2. Gwangju national museum global integration analysis

\begin{tabular}{|c|c|c|c|}
\hline Min & Max & Mean & Five convex spaces with the lowest values \\
\hline 0.63 & 2.5 & 1.57 & $\begin{array}{c}\text { Next to the upper staircase on the 2nd floor, lower right of the exhibition } \\
\text { hall on the 2nd floor, upper staircase on the 2nd floor, lower-left restroom } \\
\text { on the second floor, upper left storage on the 1st floor }\end{array}$ \\
\hline
\end{tabular}

Second, the minimum, maximum, and mean local integration of the Gwangju National Museum were 0.3, 0.9, and 0.71, respectively. As shown in [Table 3], the convex spaces that show low global integration based on the local integration are spaces that are vulnerable to theft, and these spaces with low utilization and awareness are generally convex spaces of the museum's outer circulations or storage spaces. These problems can be solved by installing CCTVs or detectors in these areas.

Table 3. Gwangju national museum local integration analysis

\begin{tabular}{|c|c|c|c|}
\hline Min & Max & Mean & Five convex spaces with the lowest values \\
\hline
\end{tabular}




\begin{tabular}{|c|c|c|c|}
\hline 0.3 & 0.9 & 0.71 & $\begin{array}{l}\text { Lower right storage on the 2nd floor, lower right of the exhibition hall on } \\
\text { the 2nd floor, lower area of the exhibition hall on the 2nd floor, right side } \\
\text { of the exhibition hall on the 2nd floor, lower left of the exhibition hall on } \\
\text { the 2nd floor }\end{array}$ \\
\hline
\end{tabular}

Third, as shown in [Figure 1] and [Figure 2], this study identified the areas that are most vulnerable to theft by deriving the convex spaces with both low global and local integration based on the analyses above. Local integration and global integration quantitatively indicate the degree of spatial recognition in all of the circulations or a specific circulation. If both of these values are low, the utilization rate is expected to be low because the recognition or awareness is lower than other spaces. As a result, areas with low utilization can be areas vulnerable to theft in museums. Theses spaces with low awareness and integration are generally warehouses or storage spaces. The problems in such areas vulnerable to theft should be solved by installing CCTVs and detectors or by installing staff facilities to control access.

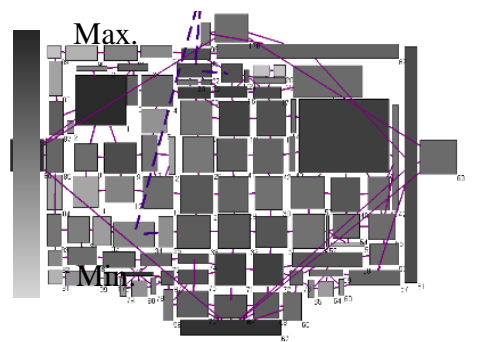

a) Global integration

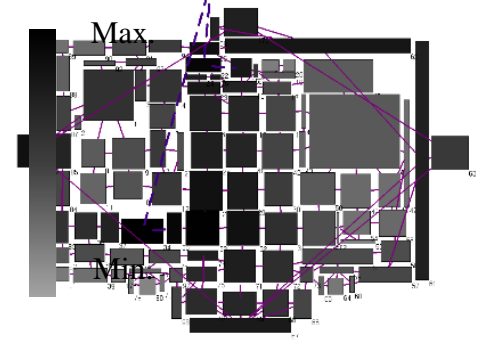

b) Local integration

Figure 1. Global and Local Integration results using space syntax

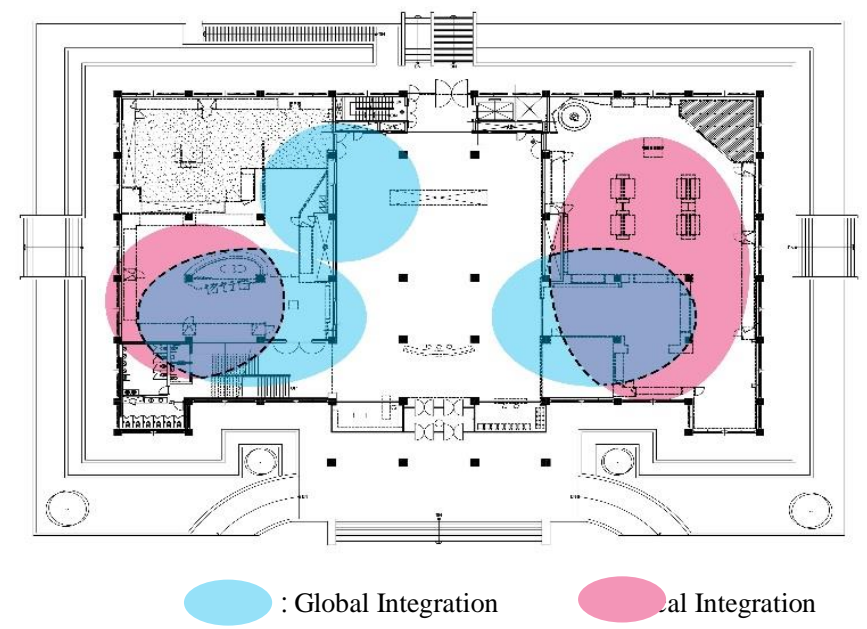

Figure 2. Analysis of areas vulnerable to theft through global and local integration

\section{Conclusion}

This is an analytical study that focused on the areas vulnerable to theft according to the spatial structure of museums, and analyzed the building area, spatial composition, and circulation of an actual museum in Korea. The main findings are as follows. 
First, this study derived the convex spaces with low global integration values in the museum. The information desks and corridors that require high integration in each space show average values, but the convex spaces of the outer perimeter and storage spaces show low values. These convex spaces are vulnerable to theft because they have low accessibility to all other spaces and low significance in terms of spatial structure. Therefore, additional control facilities need to be installed in these vulnerable areas.

Second, this study derived the convex spaces with low local integration values in the museum. These areas were generally the convex spaces of the museum's outer circulations or storage spaces, and CCTVs and detectors should be installed to resolve theft-related issues related.

This study has its significance because it analyzed the areas vulnerable to theft according to the spatial structure of a museum and built basic data for the design of museums. However, this study has limitations because it derived the areas vulnerable to theft by relying on space syntax, which is based on spatial structure and hierarchy. Further research should be conducted in the future using multiple methods.

\section{References}

[1] M. H. Park, "Museum exhibit space structure and diversity of visitors movement," The Korean Institute of Culture Architecture, vol.66, pp.3-8, (2019)

[2] S. W. Jeong, "Classification system of collections and distribution of storages in domestic museum of historic relics," Journal of Korean Institute of Interior Design, vol.15, no.2, pp.138-150, (2006)

[3] Y. R. Kim and J. W. Chae, "An analysis of museum exhibition space using space syntax theory," Journal of the Korea Institute of Spatial Design, vol.14, no.2, pp.81-90, (2019)

[4] H. R. Ko and J. A. Choi, "A study of stair-shaped open space design tendencies as a reinforcement element of museum publicity," Journal of the Korea Institute of Spatial Design, vol.14, no.6, pp.241-257, (2019)

[5] Y. G. Cha, "Security status and system of domestic museums," Korean Society of Museum Architecture, vol.5, pp.5-18, (2003)

[6] S. W. Jung, "A study on the design guidelines for the spatial planning of conservation area in museums," Korean Society of Interior Design, vol.20, no.5, pp.197-207, (2011)

[7] Y. S. Kim, "A study on the spatial organization of exhibition spaces in museums," Journal of the Architectural Institute of Korea, vol.11, no.11, pp.78-89, (1995)

[8] S. W. Jeong, "A study on the relationship between the spatial configuration and visitor's movement in museum," Journal of the Architectural Institute of Korea Planning \& Design, vol.22, no.10, pp.167-175, (2006)

[9] D. H. Kim, "A study on the complex cultural space in museum," Journal of International Association for Glocal Culture, vol.2, no.3, pp.1-22, (2015)

[10] Y. R. Kim and J. W. Chae, "an analysis of museum exhibition space using space syntax theory," Journal of the Korea Institute of Spatial Design, vol.14, no.2, pp.81-91, (2019)

[11] Y. L. Kim and J. W. Chae, "An analysis of museum exhibition space using space syntax theory," Korean Society for Space Design, vol.14, no.2. pp.81-91, (2019) 